\title{
NUMERICAL MODELING OF TEMPERATURE FIELDS IN AN AIR- CONDITIONED SHOPPING COMPLEX
}

\author{
Sudhangshu Sarma ${ }^{1}$, O. P. Jakhar ${ }^{2}$ \\ ${ }^{I} P$ G Student, Department of Thermal Engineering, Government Engineering College Bikaner, Rajasthan \\ ${ }^{2}$ Associate Professor, Department of Mechanical Engineering, Government Engineering College Bikaner, Rajasthan
}

\begin{abstract}
In the paper three-dimensional case of temperature distribution has been presented for an air-conditioned single story shopping complex. Numerical modeling has been used to analyze effect of varying inlet temperature on temperature distribution inside the shopping complex under standard conditions. Again impact of solar radiation on the building roof and outside walls is also taken into account. Calculations are carried out in an empty shops using specialized computational fluid dynamics (CFD) software FLUENT 14.5. The main goal is to find optimal inlet air temperature in order to reduce the energy consumption.
\end{abstract}

Keywords: Air-Conditioning, CFD Simulation, Solar Radiation, Temperature Distribution

\section{INTRODUCTION}

Due to the present environmental situation, energy saving has become the leading drive in modern research. Study of temperature distribution inside an air-conditioned building is an effective method to save energy and to improve indoor thermal comfort. Temperature distribution is strongly influenced by the inlet supply air temperature. Therefore in this paper four different supply air temperatures are considered to find out the optimal inlet temperature of the air-conditioner.

Many researches have been directed at building air temperature distribution already. Hanibusi et al. ${ }^{[1]}$ (2000) deals with the prediction temperature field in a model room heated by an air room conditioner. Chrvat et al. ${ }^{[2]}$ (2001) studied temperature fields and air flow in a glazed attic considering the solar radiation. Begdouri et al. ${ }^{[3]}$ (2005) analyzed the position of air-conditioner on thermal comfort in an office room. Energy estimations are also performed and evaluated in this study. Kurian et al. ${ }^{[4]}$ (2008) showed that dimming with a fuzzy logic.

Based window blind controller provides complete optimization of thermal comfort in the interior with energy savings. Khalifia et al. ${ }^{[5]}$ (2014) applied the finite volume method to study the effect of air inlet and exit on indoor air movement. Jusoh et al. ${ }^{[6]}$ (2014) using CFD tool analyzed a thermal building with non- uniform thermal environment.

\section{MODEL OF THE SHOPPING COMPLEX}

Here we are studying a single story shopping complex $(20 \mathrm{~m} \times 15 \mathrm{~m} \times 3 \mathrm{~m})$ having 11 shops. Dimension of each shop is different. In all the corner shops there are two windows air-conditioner are fitted and an air-conditioner is installed.in each of the other shops. Importance is given temperature field of the corridor as passage of customers are frequent in this domain.

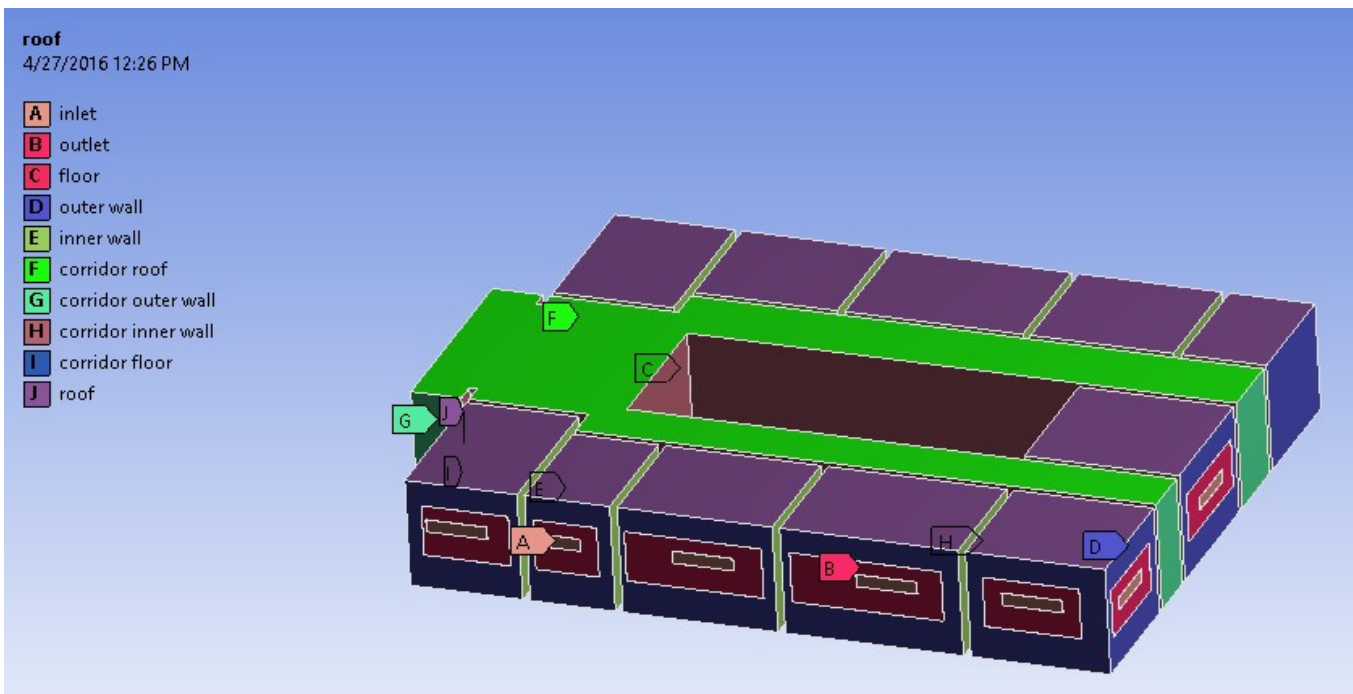

Fig-1: Model of the shopping complex 


\section{MATHEMATICAL MODEL}

The governing equation expressing the conservation of mass, momentum and energy with turbulence energy and energy dissipation equation are as follows-

Continuity equation:

$\frac{\partial\left(\rho u_{i}\right)}{\partial x_{i}}=0$

Conservation of Momentum equation:

$$
\begin{aligned}
\frac{\partial\left(\rho u_{i}\right)}{\partial t}+\frac{\partial\left(\rho u_{i} u_{j}\right)}{\partial x_{j}} & \\
= & \frac{\partial P}{\partial x_{j}}\left[\left(\mu+\mu_{t}\right)\left(\frac{\partial u_{i}}{\partial x_{j}}+\frac{\partial u_{j}}{\partial x_{i}}\right)\right] \\
& -\rho \beta\left(T-T_{\infty}\right) g_{i}
\end{aligned}
$$

Conservation of Energy equation:

$\frac{\partial \rho \mathrm{T}}{\partial \mathrm{t}}+\frac{\partial\left(\rho \mathrm{u}_{\mathrm{j}} \mathrm{T}\right)}{\partial \mathrm{x}_{\mathrm{j}}}=\frac{\partial \mathrm{P}}{\partial \mathrm{x}_{\mathrm{j}}}\left[\left(\frac{\mathrm{k}}{\mathrm{C}_{\mathrm{p}}}+\frac{\mu_{\mathrm{t}}}{\sigma_{\mathrm{t}}}\right) \frac{\partial \mathrm{T}}{\partial \mathrm{x}_{\mathrm{j}}}+\mathrm{S}_{\mathrm{T}}\right.$

Turbulence Energy equation (k-equation):

$\frac{\partial \rho \mathrm{k}}{\partial \mathrm{t}}+\frac{\partial\left(\rho \mathrm{u}_{\mathrm{i}} \mathrm{k}\right)}{\partial \mathrm{x}_{\mathrm{j}}}=\frac{\partial}{\partial \mathrm{x}_{\mathrm{j}}}\left[\left(\mu+\mu_{\mathrm{t}}\right) \frac{\partial \mathrm{k}}{\partial \mathrm{x}_{\mathrm{i}}}\right]+\mu_{\mathrm{t}} \frac{\partial \mathrm{u}_{\mathrm{i}}}{\partial \mathrm{x}_{\mathrm{j}}}\left(\frac{\partial \mathrm{u}_{\mathrm{i}}}{\partial \mathrm{x}_{\mathrm{j}}}+\frac{\partial \mathrm{u}_{\mathrm{j}}}{\partial \mathrm{x}_{\mathrm{i}}}\right)$

Turbulence Energy Dissipation equation ( $\varepsilon$-equation):

$$
\begin{aligned}
\frac{\partial(\rho \varepsilon)}{\partial \mathrm{t}}+\frac{\partial\left(\rho \mathrm{u}_{\mathrm{i}} \varepsilon\right)}{\partial \mathrm{x}_{\mathrm{j}}} & =\frac{\partial}{\partial \mathrm{x}_{\mathrm{j}}}\left[\left(\mu+\frac{\mu_{\mathrm{t}}}{\mathrm{C}_{\varepsilon}}\right) \frac{\partial \varepsilon}{\partial \mathrm{x}_{\mathrm{j}}}\right] \\
& +\frac{\varepsilon}{\mathrm{k}} \mathrm{C}_{1} \mu_{\mathrm{t}} \frac{\partial \mathrm{u}_{\mathrm{i}}}{\partial \mathrm{x}_{\mathrm{j}}}\left(\frac{\partial \mathrm{u}_{\mathrm{i}}}{\partial \mathrm{x}_{\mathrm{j}}}+\frac{\partial \mathrm{u}_{\mathrm{j}}}{\partial \mathrm{x}_{\mathrm{i}}}\right) \\
& -\mathrm{C}_{2} \rho \frac{\varepsilon^{2}}{\mathrm{k}}
\end{aligned}
$$

In the above equations $\mathrm{C}_{1}, \mathrm{C}_{2}, \mathrm{C}_{\mathrm{p}}, \sigma_{\varepsilon}, \sigma_{\mathrm{t}}$ and $\sigma_{\mathrm{c}}$ are constant of $\mathrm{k}-\varepsilon$ model.

\section{BOUNDARY CONDITIONS}

Constant air inlet velocity $2 \mathrm{~m} / \mathrm{s}$ is considered.

Four different Inlet temperatures $15^{\circ} \mathrm{C}, 18^{\circ} \mathrm{C}, 20^{\circ} \mathrm{C}$ and $24^{\circ} \mathrm{C}$ are taken.

Value of solar radiation for horizontal surface is $0.951 \mathrm{~kW} / \mathrm{m}^{2}$ and for side walls average solar radiation is $0.2228 \mathrm{~kW} / \mathrm{m}^{2}$ at external air temperature $39.1^{\circ} \mathrm{C}^{[7]}$

Heat transfer due to convection and radiation through the roof and the outer walls of the building which are exposed to the Sun are defined by-

$\mathrm{q}=\mathrm{h}\left(\mathrm{T}_{\mathrm{A}}-\mathrm{T}_{\mathrm{W}}\right)+\varepsilon_{\mathrm{e}} \sigma\left(\mathrm{T}_{\infty}{ }^{4}-\mathrm{T}_{\mathrm{W}}{ }^{4}\right)$
Again heat transfer due to convection through the inner walls and the floor of the building are defined by-

$\mathrm{q}=\mathrm{h}\left(\mathrm{T}_{\mathrm{A}}-\mathrm{T}_{\mathrm{W}}\right)$

Where

$\mathrm{h}=$ convection heat transfer coefficient at the external wall surface

$\mathrm{T}_{\mathrm{A}}=$ External air temperature

$\mathrm{T}_{\mathrm{W}}=$ External wall surface temperature

$\varepsilon_{\mathrm{e}}=$ External emissivity

$\sigma=$ Stefan-Boltzmann's constant

$\mathrm{T}_{\infty}=$ External radiation temperature

\section{RESULT AND DISCUSSION}

Simulation was carried out for all the four cases for the supply air temperature $15^{\circ} \mathrm{C}, 18^{\circ} \mathrm{C}, 20^{\circ} \mathrm{C}$ and $24^{\circ} \mathrm{C}$ respectively. Temperature profiles are shown in the horizontal plane at $\mathrm{Z}=1 \mathrm{~m}$ and temperature distributions are plotted both side of the corridor at $\mathrm{Y}=3$ and $\mathrm{Y}=-3 \mathrm{~m}$

Case I: Supply air temperature $15^{\circ} \mathrm{C}$

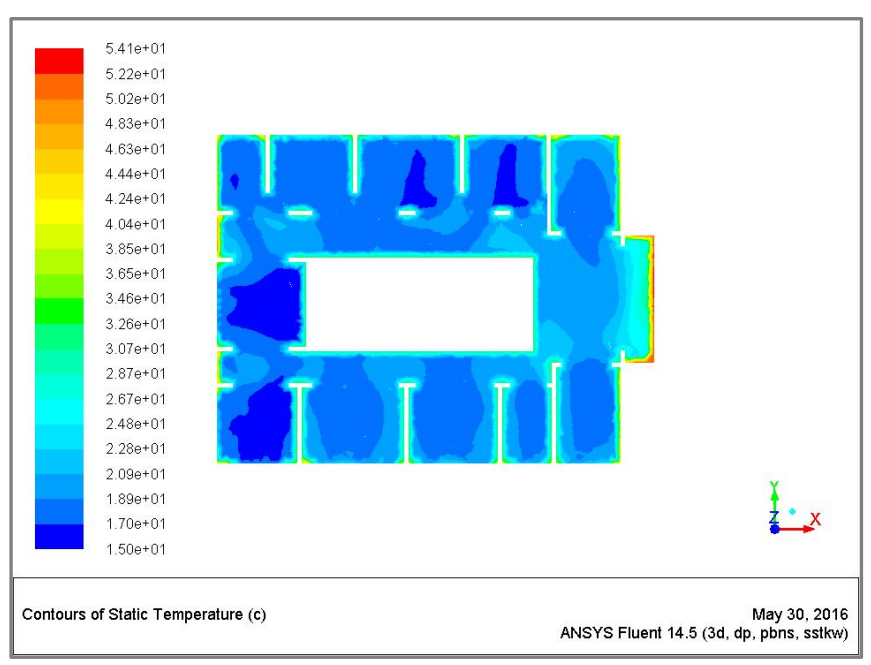

Fig-2: Temperature field in at $\mathrm{Z}=1 \mathrm{~m}$

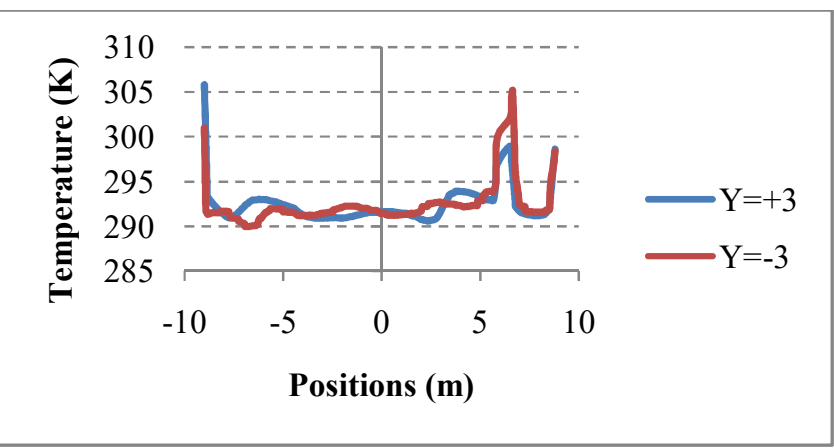

Fig-3: Temperature profile at $\mathrm{Y}=3$ and $-3 \mathrm{~m}$ 
Case II: Supply air temperature $18^{\circ} \mathrm{C}$

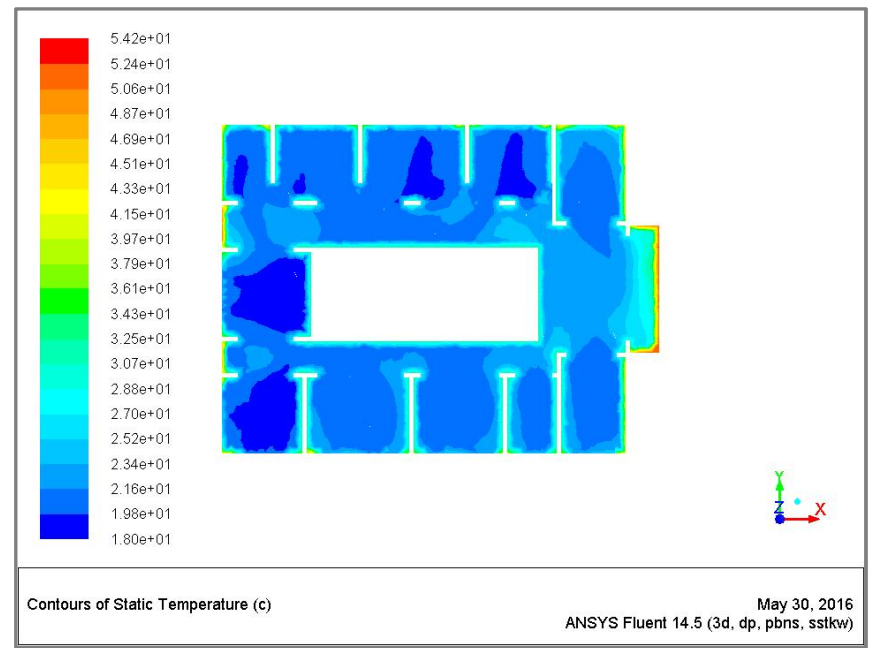

Fig-4: Temperature field at $Z=1 \mathrm{~m}$

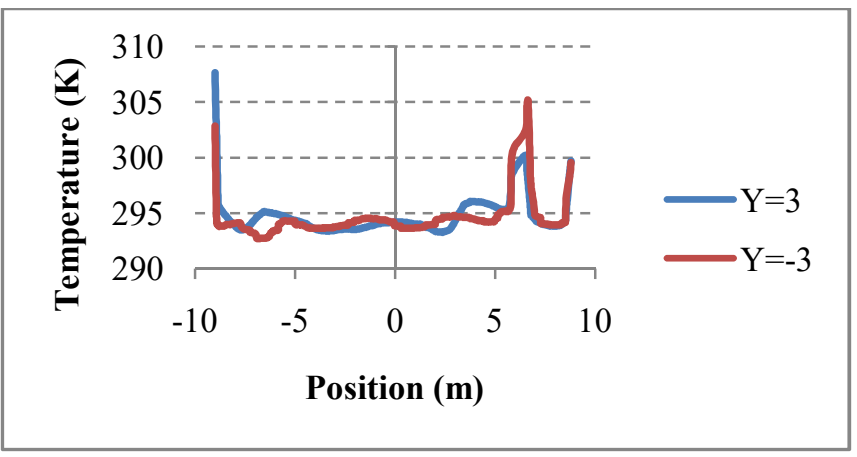

Fig-5: Temperature profiles at $\mathrm{Y}=3$ and $-3 \mathrm{~m}$

Case III: Supply air temperature $20^{\circ} \mathrm{C}$

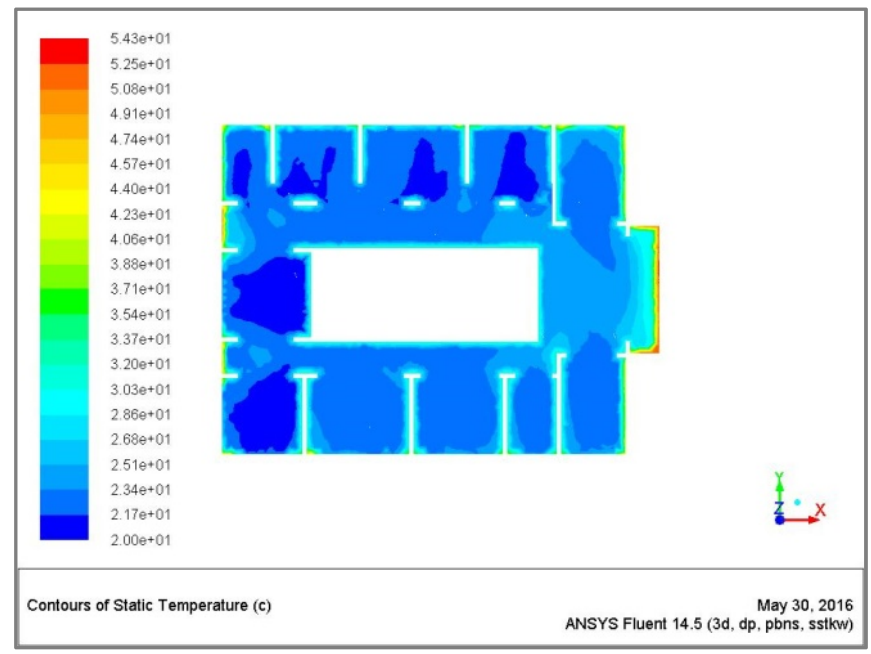

Fig-6: Temperature field at $Z=1 \mathrm{~m}$

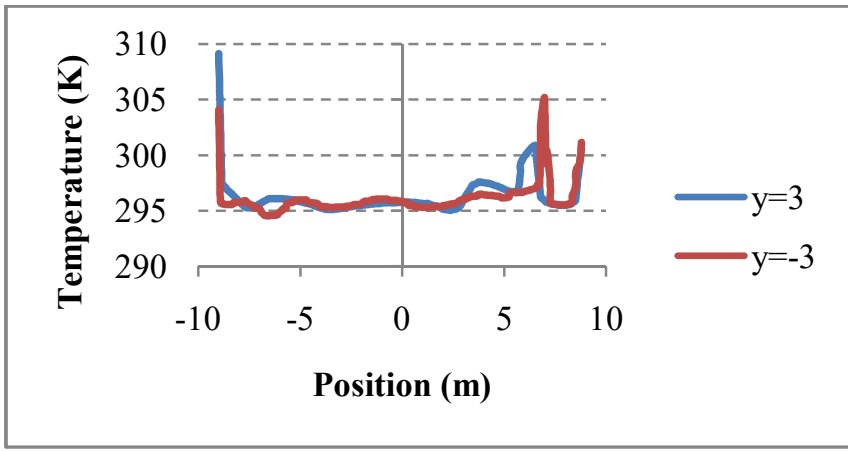

Fig-7: Temperature profiles at $\mathrm{Y}=3$ and $-3 \mathrm{~m}$

Case IV: Supply air temperature $24^{\circ} \mathrm{C}$

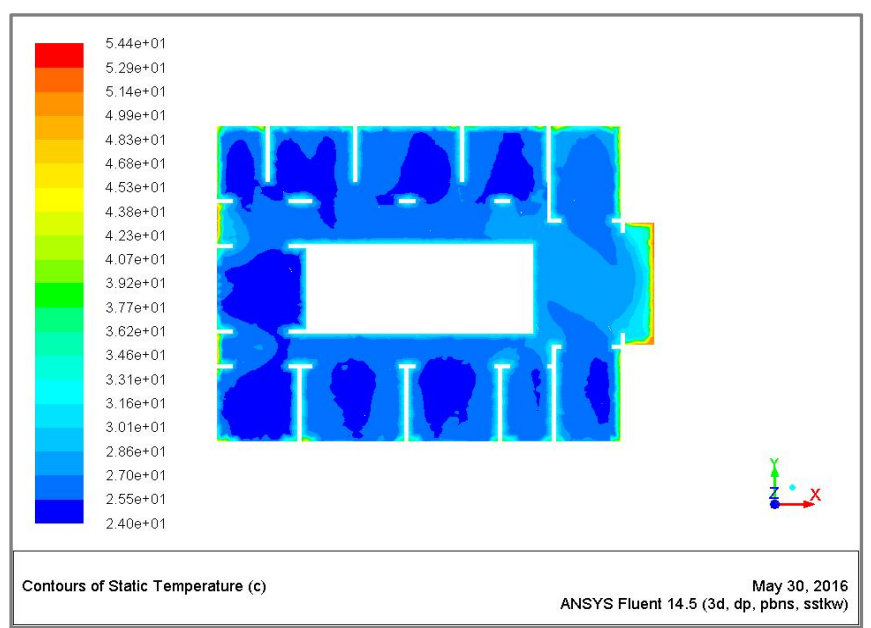

Fig-8: Temperature field at $\mathrm{Z}=1 \mathrm{~m}$

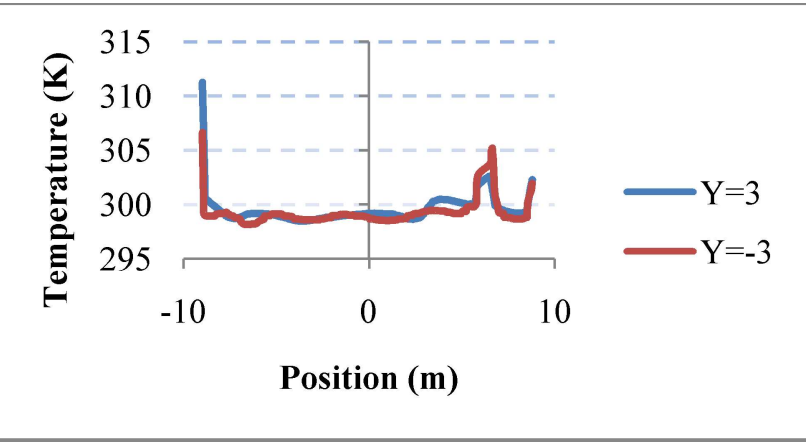

Fig-9: Temperature profiles at $\mathrm{Y}=3$ and $-3 \mathrm{~m}$

In Fig 10 and Fig 11 comparison graphs are shown for all four cases at $\mathrm{Y}=3$ and $\mathrm{Y}=-3$ respectively.

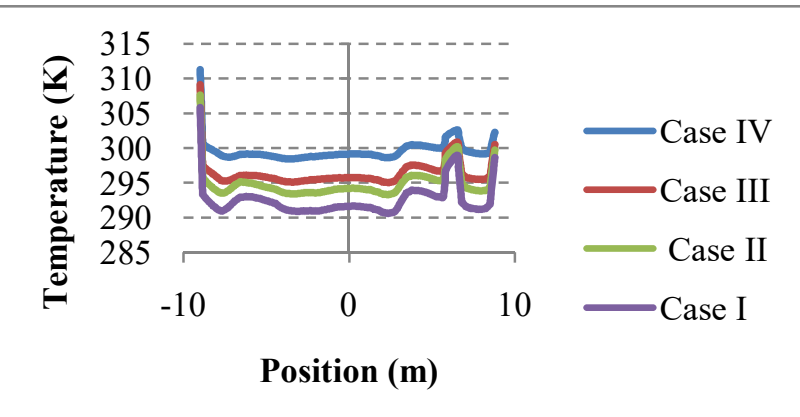

Fig-10: Temperature profiles at $\mathrm{Y}=3$ 


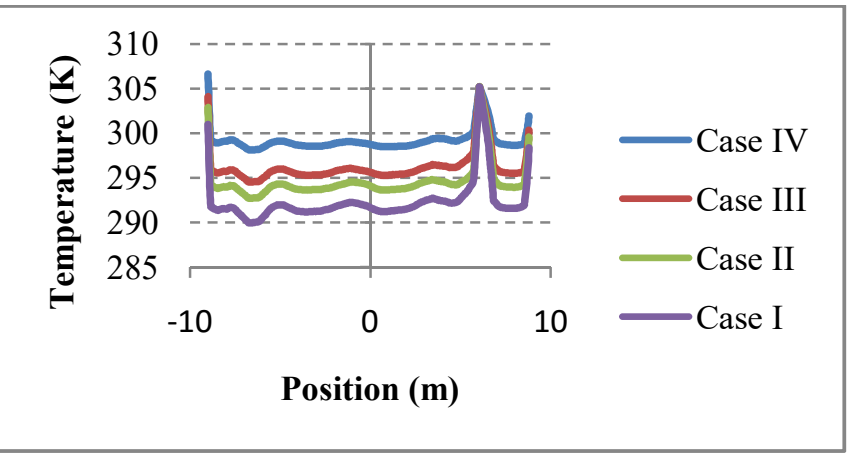

Fig-11: Temperature profiles at $\mathrm{Y}=-3 \mathrm{~m}$

As recommendation of ASHRAE 55-2010 comfort temperature ranges in summer is $23-25.5^{\circ} \mathrm{C}$ for Relative Humidity $60 \%$ and $24.5-28^{\circ} \mathrm{C}$ for relative humidity $30 \%{ }^{[8]}$. In this computational study mass-weighted average temperatures for Case I, II, III and IV are $19.27^{\circ} \mathrm{C}, 21.72^{\circ} \mathrm{C}$, $23.27^{\circ} \mathrm{C}$ and $26.52^{\circ} \mathrm{C}$ respectively. Hence Case I and II provides lower temperatures than the comfort temperature limit. Again mass-weighted average temperature of Case IV will go high further if we considered the heat loads (like person, lights, computers etc.) inside the shops. So Case IV does not provide the required thermal comfort temperature. But in Case III, average mass-weighted temperature is $23.2702^{\circ} \mathrm{C}$ soeven after consideration of some heat loads case III will fulfill the recommended comfort temperature range.

As per the study of ACEEE (American Council of Energy Efficiency Economy), increase of each ${ }^{\circ} \mathrm{C}$ can save $3-5 \%$ of units consume ${ }^{[9]}$. Case III consumes more energy than case IV but it consumes $20.75 \%$ and $9.47 \%$ less energy than Case I and II respectively.

So from the above analysis it can be concluded that the overall energy consumption and comfort thermal temperature is optimum in Case III. So supply air temperature of air-conditioner is recommended for this shopping complex.

\section{CONCLUSION}

In the current investigation of modeling of temperature field distribution an efficient supply air temperature is determined. It is intended to contribute to the effort towards designing buildings that provide more comfortable inside environment and for obtaining maximum energy savings.

Further study is still required as the actual physical airconditioned building is depends on various factors like air speed, relative humidity etc. Again in this analysis it is seen that numbers and positions of inlets in a room drastically changed the temperature profile. So these should be optimized.

\section{REFERENCES}

[1] Hanibuchi H.Hokoi S., 2000,Experimental and Numerical Prediction of Velocity and Temperature Fields in A Room Heated By A Room Air-Conditioner
[2] Charvat P., Jaros M., Katolicky J And Svorcik P, 2001, Numerical Modeling Of Airflow And Temperature Fields In A Glazed Attic, Seventh International IBPSA Conference Rio de Janeiro, August, 2001, Brazil, pp. 13-15

[3] Begdouri Hamza, 2005, Analysis of the impact of the location of a window type air-conditioner on thermal comfort in an office room, Graduate Theses and Dissertations, pp.13-20

[4] Kurian CP, Aithal RS, Bhat J, George VI (2008a). Robust control and optimization of energy consumption in daylight-Artificial light integrated schemes. Lighting Research and Technology, 40(1): 7 - 2

[5] Khalifa N. H., Hamad J A, Faraj J.J.,Ahmed Q A, 2014, A study of the Effect of Air Inlet and Exit on Indoor Air Movement, Journal of Engineering, Volume 20.

[6] Jusoh N., Bakar A. R., Ismail R. A., Ali S. Z. T.,2015, Computational analysis of thermal building in a nouniform thermal environment, Energy Procedia 68 (2015), pp. 438-445

[7] mnre.gov.in/solar-energy/ch-4.pdf,Thermal Performance of Buildings, Appendix - Iv.2

[8] American Society of Heating, Refrigerating, and Air Conditioning Engineers (ASHRAE) Standard 55 - 2010 "Thermal Environmental Conditions for Human Occupancy". 